\title{
Social media for health care managers: creating a workshop in collaboration with the UBC Centre for Health Care Management
}

\author{
Kevin Read and Dean Giustini
}

\section{Introduction}

This paper describes the early stages of creating an online social media course for health care managers (HCMs), a collaborative project undertaken by two health librarians for the Centre for Health Care Management (CHCM) at the University of British Columbia (UBC) Sauder School of Business. The early planning for the course (actually a condensed five-week workshop) was an iterative, heuristic process that built substantially on the literature, environmental scans of relevant websites, and existing content that was developed for two other courses taught by one of the authors.

\section{Scanning the environment}

“... personalized medicine is coming... it's powerful and has the ability to change the way we take care of people in the healthcare system" [1]

In June 2011, the authors were approached by the CHCM about the idea of creating a new online workshop for Canadian health care managers. Firstly, the authors completed an environmental scan of health care managers' use of social networking sites, identified key experts in the field, and used various search methods on websites containing grey reports and literature. As part of this process, the authors examined courses offered by the Canadian College of Health Leaders (CCHL), the American College of Healthcare Executives (ACHE), and the United Nations Institute for Training and Research (UNITAR). To develop a more nuanced, detailed view of social media, we performed searches in the major medical and business-related databases to cumulate as much research as possible and to establish a knowledge base from which to build course content (Appendix A).

\section{Social media and evidence-based practice (EBP)}

"...this is the beginning of a beautiful friendship" [2]

The value of social media in health and medicine has been the topic of some debate and controversy in recent years [3, 4]. However, medicine 2.0 and informatics conferences are now held internationally to share findings from social media research $[5,6]$. A cursory glance at papers delivered at medicine 2.0 conferences reveals new evidence of social media's value in patient monitoring, clinical trial recruitment, and knowledge sharing. According to Metzger et al., "evidence-based medical information can take appropriate advantage of community intelligence spawned by web 2.0 technologies, resulting in the ideal combination of scientifically sound, high-quality information... and imbued with experiential insights from a multitude of individuals" [7]. In 2009, for example, before the global spread of H1N1, the U.S. Centers for Disease Control had a Twitter account with 2500 followers, but soon their numbers grew to 370000 - a huge information-sharing and surveillance network whose tweets are now a part of $\mathrm{H} 1 \mathrm{~N} 1$ history. Some health organizations, such as the renowned Mayo Clinic, the Cleveland Clinic, and Seattle's Swedish Medical Center, see the importance of social media in evidence-based care and have reacted accordingly $[8,9]$. These organizations now employ full-time experts to manage their social media activities. According to Bennett's list of U.S. Hospitals Using Social Media, 1200 hospitals use social media and maintain 4000 different accounts [10]. Canadian numbers are more modest at just under 300 hospitals using social media [11].

Heightened awareness of web 2.0 has prompted some managers to consider social media for public relations (PR) purposes. Organizations may choose to bring in an outside expert such as a social media manager in the early planning stages. At the very least, hospitals in Canada's

K. Read. MAS/MLIS (candidate), University of British Columbia, BC, Canada.

D. Giustini. ${ }^{1}$ MLS, MEd., Biomedical Branch Librarian, University of British Columbia, BC, Canada.

${ }^{1}$ Corresponding author (e-mail: dean.giustini@gmail.com). 
major urban centres can use social media as part of their community outreach. However, we suggest that more can be done; social media gives hospitals an identity beyond its name and standards of care. Hospital involvement in social media ranges widely in Canada from creating profiles on Facebook and Twitter to writing policies to guide employees' use of certain tools - but nothing close to a best practice standard has emerged.

The demand for continuing education (CE) courses in social media seems to be on the rise. Even before web 2.0, social networking has been shown to improve the health, well-being, and economic development of communities. In recognition of that, the UBC School of Population and Public Health developed a 13-week graduate-level public health course in social media to impart to students new literacies in public health [12]. Upon learning of this course, the UBC Centre for Health Care Management approached one of the authors to discuss a similar condensed version of the course for health care managers.

\section{Why should HCMs use social media?}

"...good news generated by an organization strengthens its reputation in the marketplace and among policymakers and influencers..." [13]

\section{Digital reputation management and identity}

The authors' goal is to identify the tools, trends, risks, and benefits of using social media. It is important to understand how HCMs in Canada are using social media, and how they manage the resulting information flows. On review of practices, we were struck by how unevenly social media seems to be used in Canadian health care. In our website scanning, we identified discussions about risk management on Twitter, but evidence in the literature was minimal. That aside, some health care managers and physicians have acknowledged the untapped potential of social media in building a digital reputation $[14,15]$. Abraham, for instance, says that in the competitive American environment, consumers decide where they seek care based on what is said online about health organizations [16].

Given the differences in our two systems, Canadian consumers are not interested in assessing patient care in quite the same way. However, what seems clear is that consumers everywhere are using social media to position themselves at the centre of care and are not satisfied with unidirectional conversations with health care teams. In opening up discourse, Abraham warns readers about the potential risks in engaging in dialogue on social media [16]. That's a theme Cain picks up in 2011 suggesting openness can be especially dangerous when using Facebook and Twitter [17]. Open sharing can negatively influence public perceptions when inaccurate or misleading comments are made. More problematic is any damage done to someone's online reputation, which can be irreversible. Sarringhaus hints at the idea that reputation building must not be left to experimentation and that strategic approaches must be used [18]. The flow of information in the digital age provides a way to extend a clinician's reach into their communities - but those conversations will have to be interactive if they are to be taken seriously.

\section{Patient engagement}

"Healthcare 2.0 has evolved to users finding ad-hoc ways to connect...creating Web-connected diaries and blogs... and sharing journals to address various medical conditions outside of the healthcare providers' offices..." [19]

Much of the unidirectional communication that happens at hospitals and clinics is a remnant of a paternalistic age. Now, the reach of online communication heralds more patient-centred models of care. In fact, some hospitals consult patients in new digital ways that will ultimately increase their participation. For example, Sarringhaus in 2011 [18] and Eysenbach in 2008 [20] recommend connecting peer-to-peer communities where individual actors contribute their unique problem-solving skills. Social media provides patients, for example, with a way to voice concerns while contributing their unique solutions. When patients share observations, their collective wisdom can yield clinical insights well beyond the expertise of single physicians [20]. In fact, Sarasohn-Kahn reports that the top five reasons consumers use social media are to see what other consumers are saying about treatments; research other consumers' experiences; learn new skills and manage conditions; get emotional support; and build awareness for a disease or cause [21]. Moreover, Fordis et al. point out that patients inadvertently contribute to knowledge creation by virtue of using social media, which can be mined for needed information later [22]. This data informs clinicians, clinical investigators, and pharmaceutical firms about the benefits and harms of treatments [22]. This example shows how patients contribute to research in new and meaningful ways, without ever leaving home. Other reliable ways HCMs can use Facebook and Twitter include setting up virtual suggestion boxes where influence can be built online with patients and potential donors [18]. Twitter has been used in the United States, for example, to elicit opinions from patients about health reform [23]. Certain patient blogs are monitored for emerging threats or concerns based on the views of readers [23]. While few clinicians have the time to monitor conversations on Facebook and Twitter, this can be undertaken by health librarians - and HCMs can be advised as needed.

The applied research provides a view of social media for patients - what the experts call health 2.0. Many health 2.0 initiatives provide online psychosocial support for patients coping with smoking cessation, dieting, and chronic illness. PatientsLikeMe, for example, brings newly diagnosed patients with life-altering diseases together in an online community of sharing and support [24]. Similarly, RevolutionHealth's goal is to expand the virtual hub of online support for patients worldwide [19]. The literature indicates that communities such as PatientsLikeMe and RevolutionHealth are empowering to consumers, improve patient-doctor relationships, and improve quality of care [24]. Moreover, they provide decision-makers with ample evidence should they wish to pilot new social media initiatives within their own institutions. 


\section{Doctor-patient interactions}

A recurring theme in social media refers to the benefits that come from increased interactions with people. Hello Health and Kaiser Permanente, for example, are sites created specifically to increase patient-physician interactions. Hello Health is designed for physicians as a secured portal to manage and maintain patient contact [24]. For a small fee, patients email, instant message (IM), and video chat with their doctors. Direct lines of communication serve to relieve stress as they provide patients with a simple mechanism to share their minor complaints and questions. Kaiser Permanente has created webpages for its physician staff so that patients can get to know them [24]. These pages function like Facebook where users can share their personal information with others [24]. These tools are clearly evidence of how patient-physician relationships are changing in the United States, but we are unclear about whether similar open, transparent communication would work equally well in Canada. This is an area for further research.

\section{Total Quality Improvement}

"... every organization needs to reduce costs...with most social media options free to users, such as Facebook, Twitter,

Linkedln, blog hosting sites and YouTube, the costs associated are mainly those of labor in the marketing and human resources departments..." [25]

It should come as no surprise that HCMs are seeing the value of using social media for total quality improvement (TQI) purposes. Typically, TQI is an internally driven process that ensures health organizations provide adequate levels of care. By drawing on the power of social media, HCMs can monitor patients more closely and respond to their needs accordingly. In their research, Zeng et al said that social media can also be "mashed" together so that composite data profiles can be created [25]. Using Google maps, HCMs can even generate data from hospital evaluations to compare health organizations across an entire region. Mashup tools provide HCMs with new ways to measure and evaluate TQI. In fact, by combining data from social media platforms, HCMs can also improve their evaluation processes.

\section{How do HCMs use social media?}

\section{CEO bloggers in the United States}

Health blogging is widely used by health professionals to reach out to patients and each other. On blogs, managers have access to a range of ideas outside their regular workplace channels and can turn to other managers on the blogosphere for a second opinion. According to Malvey et al., HCMs and CEOs use blogs to communicate and to "get to the bottom line" [26]. Health blogging, however, is a "2-way street" and not meant to be a monologue. Blogs should be used to solicit feedback and share news with others; their affordances allow HCMs to maintain open dialogue with patients and employees. HCMs can be made aware of the potential of these tools in increasing the overall quality of their work.
Currently, the number of CEO bloggers in health is considerable but centred in the United States. One prominent U.S. blogger is Paul Levy, a former CEO and author of the blog Not Running a Hospital [27]. The twoway exchange on Levy's blog is emblematic of what can be achieved through successful blogging. Levy uses numerous links and categories to focus on health communities and addresses topics such as the role of blogging in medicine especially in an era of health reforms. Levy's blog speaks to engaged audiences of health consumers and providers. Many of the blogs we examined provide examples for our workshop and represent some of the best blogging practices in the American context.

\section{Confidentiality and privacy concerns}

Despite an array of advantages, social media poses a number of challenges for health organizations. In the United States, the Health Insurance Portability and Accountability Act (HIPAA) is clear about upholding standards of privacy and patient confidentiality, and rightly so. In Canada, the Personal Information Protection and Electronic Documents Act (PIPEDA) dictates data privacy and how electronic documents containing personal health information can be transmitted. For example, if physicians publish information on social media about patients in the clinic, they may be in violation of privacy if any identifiable patient traits can be discerned in postings [28]. Cain stresses that HIPAA requires identifiable patient information to be removed, made completely secure, or transmitted to approved personnel only. While it is true that social media makes it easy to transmit, the risks present considerable liability for health organizations. HCMs can take steps to protect their employers by writing formal policies to address these issues before they become problematic.

According to Bacigalupe, creating social media policies is a major part of managing health information today. $\mathrm{He}$ suggests social media policies should be written before specific tools are implemented [29]; policies should address issues of privacy, control of information, accountability, accuracy, and transparency. He points out that writing effective policies in health care requires knowledge about social media and an awareness of risks associated with information leakage can be minimized.

Some health institutions in the United States and Europe are pushing the boundaries of patient privacy and what is acceptable to broadcast. One prominent example is the Henry Ford Hospital (HFH) in Detroit, Michigan, and its use of Twitter [30]. The hospital made headlines in 2010 when it sent live surgical tweets on Twitter, and links to specific patient information from the operating room [30]. To protect themselves legally, $\mathrm{HFH}$ physicians acquired consent from their patients. By no means typical, the HFH was among the first hospitals in the world to use social media in the operating room. As creators of a workshop for the CHCM, we realize it will be important to find Canadian examples of social media being used in ways that test its ethical and legal boundaries. 


\section{HCMs and social media in a Canadian context}

"... keeping up to date on the barrage of medical information available online can be daunting, and healthcare professionals are now turning to social media to figure out how to make it easier..." [31]

It became apparent early in our research that America's health care system motivates HCMs there to use social media differently. This is due, in part, to the private and competitive elements of their system. Because our workshop is designed for Canadian HCMs, we believe it is important to provide uniquely Canadian views on social media. Although the base of evidence is weak, we see the beginnings of digital communities of practice appearing in Canada. One of the more interesting Canadian initiatives we looked at was a group using Twitter to discuss health care on a weekly basis. According to Colleen Young at the Health Care Social Media Canada website, anyone can participate in this discussion on Twitter:

"...to help improve quality, access, value and effectiveness of health care. This includes: patients, caregivers, patient advocates, healthcare professionals, not-for-profit health organizations, educators, heath content providers, health institutions, health administrators, health systems and networks, government and health policy makers." [31]

These Twitter discussions focus on specific issues of interest to participants. Questions and topics include those submitted by participants such as how to set up virtual meetings, tools to implement them, and participants' control over them [32]. As of September 2011, the central HCSM Twitter account has 7200 followers, clearly an indication of its popularity.

Canada is home to some influential experts in social media. Neil Seeman, founder of the Health Strategy Innovation Cell, for example, has garnered attention from industry, social entrepreneurs, global media, and patient advocates [33]. The Innovation Cell is a non-profit independent think-tank at Massey College whose goal is to 'explore the Web's real time 'chatter', discover trends, design tools and create change in healthcare" [33]. On the Canadian blogosphere, Ann Fuller authors SMiCH+ Social Media in Canadian Health Care which began as a vehicle for hospitals to share resources and best practices in social media [31]. Fuller says "... in my own research, I had discovered that there were many great resources available on the use of social media for U.S. hospitals, but not a lot for Canadians. Our American counterparts share resources through such blogs as Found in Cache and the Mayo Clinic Center for Social Media." The Social Media use in Healthcare blog is developed by Innovation Cell and the Change Foundation whose aim is to help health organizations use social media effectively. They provide a wealth of information and relevant links and literature on the subject.

While much of the literature reviewed consists of case studies in the United States, we discern a number of Canadians who are potential leaders in social media. Despite a lack of research, social media in Canadian health care seems to be in a period of greater adoption.
However, experts are clearly needed in order to teach HCMs (and other health professionals) how to implement social media effectively. Health librarians can be a part of the emerging expertise and should stake a claim and their rightful place as information managers in the digital age.

\section{Discussion}

The goal for our workshop is to provide examples of successful social media programs and to identify best practices for HCMs. Part of this process is to begin by exploring simple management tips and strategies and by emphasizing social media's potential. Through our literature review, we gained a better understanding of what constitutes best practice. Social media "presents opportunities and advantages and, if used properly... [can] innovate healthcare and create a competitive advantage for adopters" [18]. Further, appropriate development of social media programs "blend the current information-delivery capacity of the Internet with the more traditionally interpersonal processes for recommending providers" [16]. Examples such as Hello Health, PatientsLikeMe, and CEO bloggers are evidence of innovation and just the beginning of what is possible.

In Canada, think-tanks such as Innovation Cell and the Change Foundation provide new opportunities to increase awareness of Canadian health care. Randeree says that social media "has evolved from users finding ad-hoc ways to connect" to something more substantive [19]. While using social media in Canadian health care is slowly evolving, it will not reach its full potential without more meaningful involvement of decision-makers. The workshop for HCMs at UBC's Sauder School for Business, taught by health librarians, will teach digital literacies in social media, not merely a litany of tools. Currie states how important it is to "know your audience and where you're going"; we have gathered information about HCMs and how they make decisions [34]. In the future, we hope to see health professionals working closely with health librarians to understand the issues introduced by social media [35]. HCMs and librarians in Canada can work together to implement social media safely and effectively in the future.

\section{Conclusion}

The online workshop we are planning positions HCMs and librarians as the logical experts of social media in health care. We believe the literature reveals the value of developing strategies in using social media. We hope health librarians are taking pre-emptive steps to improve their knowledge of social media due to its future projected rates of adoption and its potential as a lifelong learning tool for health professionals. To address continuing education needs of our members, we recommend that CHLA/ABSC consider creating its own course on social media. Health librarians should have a direct impact on how social media will be adopted by health organizations. By educating themselves, health librarians can be positioned to advise health organizations about the benefits (and risks) of using social media during what seems to be a period of mass adoption. 


\section{References}

1. Friedman J. Personalized medicine: a primer for health care managers. Centre for Health Care Management, University of British Columbia. [November 9, 2010] Lecture. Videocast available from: http://chcm.ubc.ca/2010/12/08/dr-jan-friedman/.

2. Cuello C. Evidence-based medicine and social media: the beginning of a beautiful friendship. Doctors' blog: thoughts and opinion from the wards. June 21, 2011. Available from: http://doc2doc.bmj.com/blogs/doctorsblog/_evidence-basedmedicine-social-media-beginning-of-beautiful-friendship.

3. McLean R, Richards BH, Wardman JI. The effect of web 2.0 on the future of medical practice and education: Darwikinian evolution or folksonomic revolution. Med J Aust. 2007; 187(3):174-7.

4. Anonymous. 2007. Health 2.0: technology and society: is the outbreak of cancer videos, bulimia blogs and other forms of "user generated" medical information a healthy trend? The Economist. 2007;6:73-4.

5. Medicine 2.0 Congress. Available from: http://www.medicine 20congress.com/ocs/index.php/med/med2011 (accessed August 20, 2011).

6. Wikipedia. Health 2.0. Available from: http://en.wikipedia. org/wiki/Health_2.0 (accessed August 22, 2011).

7. Metzger MJ, Flanagin AJ. Using web 2.0 technologies to enhance evidence-based medical information. Journal of Health Communication. 2011;16(sup1).

8. Mayo Clinic Center for Social Media. Available from: http:// socialmedia.mayoclinic.org/ (accessed August 23, 2011).

9. Swedish Medical Center. Available from: http://www.swedish. org/About/Blog/AuthorDetail?author $=5950$ (accessed August 23, 2011).

10. Bennett E. Hospital social network list. Found in Cache blog. Available from: http://ebennett.org/hsnl/ (accessed August 23, 2011).

11. Fuller A. SMiCH - sharing info on Social Media in Canadian Health Care blog. Available from: http://www. smich.ca/?cat $=16$ (accessed August 23, 2011).

12. Giustini D. SPPH $581 \mathrm{H}$ - Social Media in Health \& Medicine. University of British Columbia. Course Syllabus. Available from: http://www.spph.ubc.ca/sites/healthcare/files/ courses/spph581H.pdf.

13. Eytan T, Benabio J, Golla V, Parikh R, Stein S. Social media and the health system. Perm J. 2011;15(1):71-4.

14. Squazzo JD. Best practices for applying social media in healthcare. Healthcare Executive. 2010;25(3):34-6, 38-9.

15. Luo JS. Managing your digital identity. Primary Psychiatry. 2010;17(8):29.

16. Abraham J, Sick B, Anderson J, Berg A, Dehmer C, Tufano A. Selecting a provider: what factors influence patients' decision making? J Healthcare Management. 2011;56(2):99114.

17. Cain J. Social media in health care: the case for organizational policy and employee education. American Journal of Health-System Pharmacy. 2011;68(11):1036-40.
18. Sarringhaus MM. The great divide: social media's role in bridging healthcare's generational shift. J Healthcare Management. 2011;56(4):235-44.

19. Randeree E. Exploring technology impacts of Healthcare 2.0 initiatives. Telemed J E Health. 2009;15(3):255-60.

20. Eysenbach G. Medicine 2.0: social networking, collaboration, participation, apomediation, and openness. Journal of Medical Internet Resesearch 2008;10(3):e22.

21. Sarasohn-Kahn J. The wisdom of patients: Health care meets online social media. California Healthcare Foundation; 2008.

22. Fordis M, Street RL. Engagement, communication, and dissemination in the era of patient-centered outcomes research: Selected articles developed from the Eisenberg conference. Journal of Health Communication. 2011;16(1): $3-9$.

23. Luo JS. Patient education in the Internet age. Primary Psychiatry. 2008;15(4):24-6.

24. Orsini M. Social media: how home health care agencies can join the chorus of empowered voices. Home Health Care Management \& Practice. 2010;22(3):213-7.

25. Zeng X, Bell PD. Web 2.0: what a health care manager needs to know. Health Care Manager. 2008;27(1):58-70.

26. Malvey D, Alderman B, Todd AD. Blogging and the health care manager. Health Care Management (Frederick). 2009; 28(2):159-64.

27. Levy P. Not Running a Hospital. Boston: runningahospital. blogspot.com. 2008. Available from: http://runningahospital. blogspot.com/.

28. O'Dell A. Health-care groups turn to social media to distribute information. Globe and Mail. 2011 Mar 28. Available from: http://www.theglobeandmail.com/life/health/ new-health/health-news/health-care-groups-turn-to-social-me dia-to-distribute-information/article1960349/print/ (accessed August 23, 2011).

29. Bacigalupe G. Is there a role for social technologies in collaborative healthcare? Families systems \& health. 2011; 29(1):1-14.

30. Holt C. Emerging technologies: Web 2.0. Health Information Management Journal. 2011;40(1):33-5.

31. Social Media in Canadian Health Care. Available from: http://www.smich.ca/ (accessed August 23, 2011).

32. \#HCSM Global. 2009. Available from: http://www.hcsm global.com/ (accessed August 23, 2011).

33. Innovation Cell. Toronto: innovationcell.com. 2009. Available from: http://innovationcell.com/wiki/Main_Page (accessed August 23, 2011).

34. Currie D. Public health leaders using social media to convey emergencies: new tools a boon. The Nation's Health. 2009; 39(6):1-10.

35. Farrell AM, Mayer SH, Rethlefsen ML. Teaching web 2.0 beyond the library: adventures in social media, the class. Med Ref Serv Q. 2011;30(3). 


\section{Appendix A}

\section{Search strategies}

We conducted searches in MEDLINE and EMBASE using the OvidSP interface. Then, ABI/Inform, Business Source Complete, Google Scholar, PubMed, Scirus and the Web of Science. Papers were imported into Mendeley where duplicates were identified and removed. A final set of articles was placed into categories and themes for analysis. Descriptions for each article were written, and new research was identified using "snowballing" and harvesting techniques.

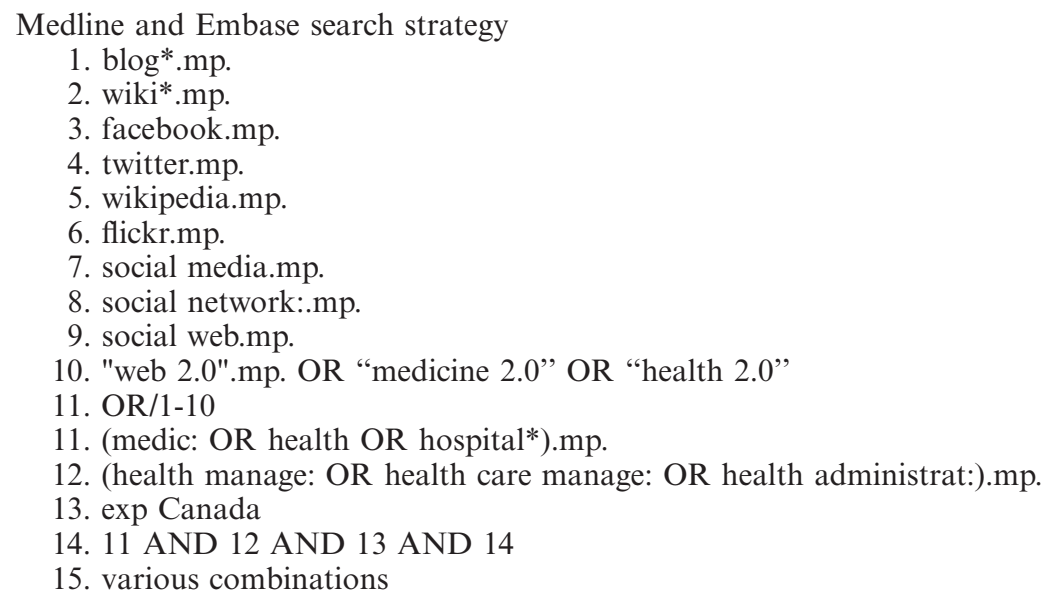

\section{Glossary}

Health care 2.0 is a more patient-centred participatory model of health care emphasizing online (public and/or private) interactions between consumers, health providers, and librarians using social media...and an ability to share medical evidence, patient data and opinion to improve health outcomes on a global scale.

Medicine 2.0 is the use of social media in medicine. A new generation of social media can be used to interact online so that health information is continually requested, consumed, and reinterpreted. The medical 2.0 environment features an intricately connected digital network of medical practitioners, where knowledge exchange is not limited by or controlled by private interests.

Web 2.0 is a term used to refer to a set of social media tools and trends since 2004.

\section{Appendix B}

\section{CEO bloggers}

Anna Roth, CEO of Contra Costa Regional Medical Center. Available from: http://safetynethospital.blogspot.com/.

Barry Ronan, Western MD Health System. Available from: http://theronanreport.blogspot.com/.

Bill Roper, CEO of University of North Carolina Health Care System. Available from: http://www.roperhealth.com/.

Dave Dobosenski, CEO of St. Croix Regional Medical Center. Available from: http://www.smallhospitalbigheart.blogspot.com/.

Marty Bonick, CEO of Jewish Hospital in Louisville. Available from: http://www.hlifeblog.com/.

Raymond Hino, CEO of Mendocino Coast District Hospital. Available from: http://coasthospitalceoforum.blogspot.com/.

Rey Spadoni, CEO of VNA of Boston. Available from: http://www.vnaceo.blogspot.com/.

Rob Colones, CEO of McLeod Health in South Carolina. Available from: http://blog.mcleodhealth.org/.

Scott Kashman, CEO of St. Joseph Medical Center. Available from: http://sjmcworld.blogspot.com/.

Todd Linden, CEO of Grinnell Regional Medical Center. Available from: http://toddlinden.blogspot.com/.

Tom Quinn, CEO of Community General Hospital. Available from: http://morethanmedicine.blogspot.com/.

\section{Former CEOs}

Action for Better Healthcare. Available from: http://actionforbetterhealthcare.com/.

John Toussaint. Available from: http://www.createhealthcarevalue.com/blog/.

Nick Jacobs. Available from: http://takingthehelloutofhealthcare.com/blog/. 


\section{Appendix C}

\section{Introduction to social media for health care managers}

\section{Background}

New social networking practices in health and medicine are changing how health care managers (HCMs) communicate in the digital age. Social media tools such as blogs, wikis, Facebook, and Twitter are changing the way we share, collaborate, and find solutions to emerging issues in Canadian health care. This online course aims to help HCMs learn how to use these tools effectively for digital communication, organizational branding (reputation management), and the improvement of patient care.

\section{Learning objectives}

Upon completion of the workshop, participants will be able to

1. Identify the potential value of social media usage (i.e., opportunities, benefits, risks)

2. Apply social media as part of strategic approaches to

- Community and stakeholder relations

- Information-management

- Current awareness of trends and patient needs

3. Recognize how to use social media effectively while mitigating risk (liability), protecting patient confidentiality and intellectual property rights for your health organization

4. Use social media to monitor health services delivery, branding, and overall management

HCMs will get the most out of this workshop by spending 2-3 hours per week reading materials, participating in online discussions, and critiquing social media (and cases from the field). Participants can complete activities at times convenient to them.

\section{Who should attend}

Canadian health care executives, managers, health professionals with management responsibilities, government managers and policy makers in health care portfolios, and communication specialists. 